\title{
Article \\ Hydrophobic Epoxy Caged Silsesquioxane Film (EP-POSS): Synthesis and Performance Characterization
}

\author{
Yanhong Fang ${ }^{1,2}$, Ping Wang ${ }^{1,2, *}$, Lifang Sun ${ }^{3}$ and Linhong Wang 4 \\ 1 State Key Laboratory of Power Transmission Equipment \& System Security and New Technology, \\ Chongqing University, Chongqing 400044, China; 20181101005@cqu.edu.cn \\ 2 School of Electrical Engineering, Chongqing University, Chongqing 400044, China \\ 3 Department of Pharmacy, Sichuan Health and Rehabilitation Vocational College, Zigong 643000, China; \\ sunlifang0524@126.com \\ 4 School of Smart Health, Chongqing College of Electronic Engineering, Chongqing 400013, China; \\ 201018044@cqcet.edu.cn \\ * Correspondence: cquwp@cqu.edu.cn
}

Citation: Fang, Y.; Wang, P.; Sun, L.; Wang, L. Hydrophobic Epoxy Caged Silsesquioxane Film (EP-POSS):

Synthesis and Performance Characterization. Nanomaterials 2021, 11, 472. https://doi.org/10.3390/ nano11020472

Academic Editors: Dong-Joo Kim and Christophe Detavernier

Received: 28 October 2020

Accepted: 4 February 2021

Published: 12 February 2021

Publisher's Note: MDPI stays neutral with regard to jurisdictional claims in published maps and institutional affiliations.

Copyright: (C) 2021 by the authors Licensee MDPI, Basel, Switzerland. This article is an open access article distributed under the terms and conditions of the Creative Commons Attribution (CC BY) license (https:/ / creativecommons.org/licenses/by/ $4.0 /)$.

\begin{abstract}
Hydrophobic films are widely used in aerospace, military weapons, high-rise building exterior glass, and non-destructive pipeline transportation due to their antifouling and self-cleaning properties. This paper details the successful preparation of hydrophobic epoxy caged sesquioxane (EP-POSS) via two steps of simple organic synthesis, along with studies on the effects of viscosity and reaction time on the reaction. Interestingly, the EP-POSS presented a large contact angle of $125^{\circ}$, indicating its excellent hydrophobicity. The surface micromorphology was observed via FE-SEM (field emission scanning electron microscopy), transmission electron microscopy (TEM), and atomic force microscopy (AFM), and the structural composition and elemental contents were analyzed via X-ray photoelectron spectroscopy (XPS) and energy-dispersive spectrometry (EDS). Thermogravimetric analysis (TGA) and differential scanning calorimetry (DSC) tests showed that EP-POSS had excellent thermal properties, and the first degradation reaction occurred at $354{ }^{\circ} \mathrm{C}$. The mechanical performance and abrasion resistance results demonstrated that EP-POSS could be used in solar panels.
\end{abstract}

Keywords: POSS; epoxy resin; nanocomposite; hydrophobicity; solar panel

\section{Introduction}

Polyhedral oligomeric silsesquioxane (POSS), suitable for preparing nano-level hybrid materials [1-4], is an organic-inorganic hybrid material with small size effect, excellent mechanical strength, low dielectric constant, and good compatibility [5-7]. POSS has been widely studied by scholars in the field of nanocomposite materials.

Recently, application prospects for POSS have been found in liquid crystal materials, ionic liquids, electronic materials, and other fields [8-10]. EP-POSS is an epoxy resin modified with POSS; its preparation methods include physical blending and chemical copolymerization [11-13]. The physical blending method refers to mixing directly and adding different proportions of POSS into epoxy resin. The incorporation of POSS into epoxy networks could result in the formation of an inert layer on the surface of the materials, which enhances the thermo-oxygen resistance of the epoxy [14]. Chemical copolymerization refers to adding POSS functionalized with different substituents into the epoxy/amine curing system to obtain epoxy resin with a hanging POSS structure. This type of method is the main one used for EP-POSS preparation currently $[15,16]$. Brus et al. synthesized epoxy/POSS nanomaterials using diglycidyl ether of bisphenol A (DGEBA) and poly(oxypropylene)diamine. Monofunctional POSS as a pendant unit and the aromatic amine 4,4-diaminodiphenylmethane as a curing agent incorporated into DGEBA epoxy crosslinking networks could achieve molecular-level dispersion of pendant POSS in epoxy 
hybrid networks [17]. Moreover, POSS has great influence in epoxy rubber mixed matrixes. The modulus of resin with pendant POSS structures increased by 1.5 orders of magnitude relative to that of unmodified resin, which was due to the pendant POSS group forming ordered crystalline domains as physical cross-links [18]. Besides this, a small amount of POSS obviously enhanced the flexural strength of EP-POSS nanocomposites, whereas the glass transition temperature $\left(\mathrm{T}_{\mathrm{g}}\right)$ value decreased with POSS introduction because there were a certain number of flexible chain segments in the polymer matrix [19]. The addition of a small amount of POSS does not significantly affect the $T_{g}$ value until it is increased to a certain amount; molecular simulations results demonstrated this conclusion [20]. In summary, the above studies showed that POSS has an excellent improvement effect on epoxy resin.

POSS is a cage structure composed of siloxane groups; the $\mathrm{Si}-\mathrm{O}$ bond energy is $425 \mathrm{~kJ} / \mathrm{mol}$, which is higher than that of the $\mathrm{C}-\mathrm{C}$ bond $(345 \mathrm{~kJ} / \mathrm{mol})$. The former structure reduces POSS's surface energy, resulting in a blocking effect on its main chain, which can be used to design hydrophobic material structures [21]. We speculated that introducing the POSS structure into epoxy resin main chains could improve the hydrophobicity of epoxy resin, with an expectation for it to be used in solar panels. To verify our assumption, a simple preparation method was used to synthesize EP-POSS nanocomposites, where POSS was the skeleton structure rather than the hanging group in the EP-POSS. The synthetic route is shown in Figure 1.

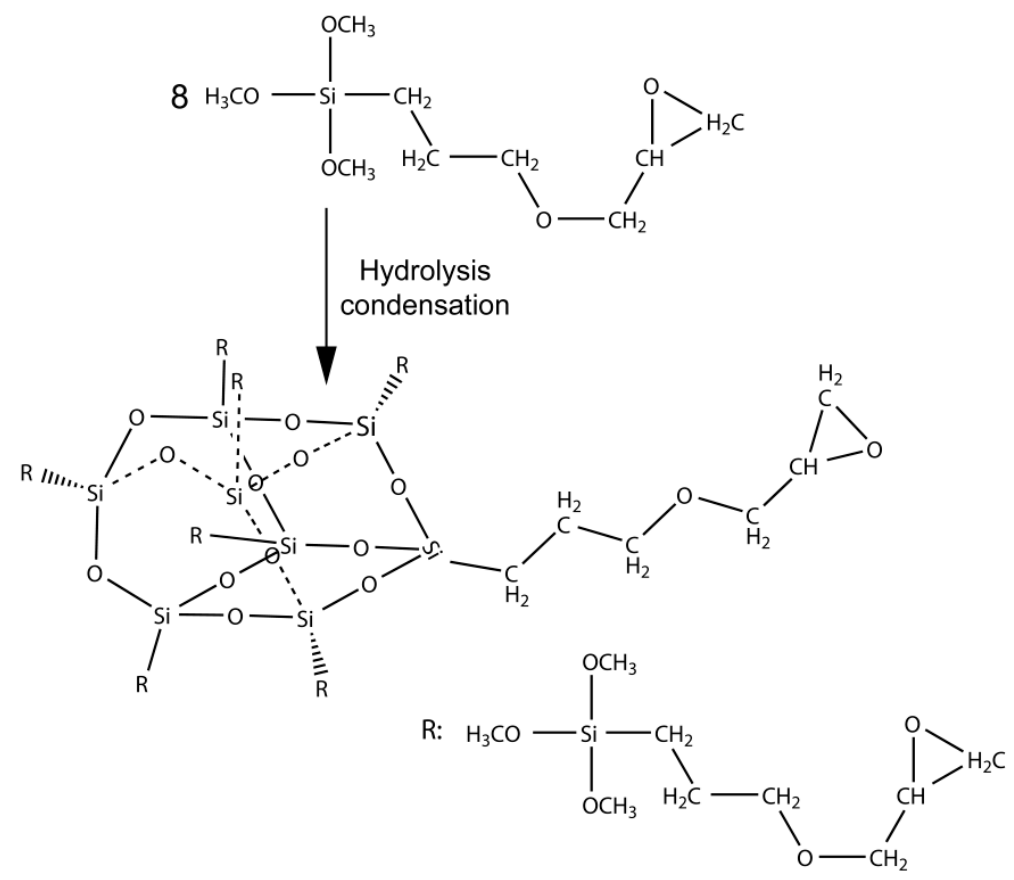

Figure 1. The synthesis route of epoxy caged sesquioxane (EP-POSS).

\section{Materials and Methods}

\subsection{Materials}

KH 560 was purchased from Chengdu Kelong chemical agent company. Tetramethyl ammonium hydroxide aqueous solution (98\%) was purchased from Beijing Couple technology co. Ltd. (Beijing, China). E51 epoxy resin was purchased from Sinopec Group. Other agents were purchased from Sigma-Aldrich (Shanghai, China). All of them were used as received.

\subsection{The Preparation of EP-POSS}

Quantities of $100 \mathrm{~mL}$ of isopropanol, $14 \mathrm{~g}$ of $4 \%$ tetramethylammonium hydroxide aqueous solution, $100 \mathrm{~mL}$ of xylene, and $60 \mathrm{~g}$ of $\mathrm{KH} 560$ were added into a $250 \mathrm{~mL}$ three-port 
flask equipped with a thermometer, a stirrer, and a drip funnel. Then, the KH560 xylene solution was added into the reactor with stirring, completing the addition within $30 \mathrm{~min}$. The solution was then kept under continuous stirring at room temperature for $24 \mathrm{~h}$. The refluxing reaction was carried out in an $80^{\circ} \mathrm{C}$ water bath for $2 \mathrm{~h}$, the $\mathrm{pH}$ value was adjusted to neutral, and the mixture was stirred at room temperature for $1 \mathrm{~h}$. Then, distillation was carried out to remove the solvent. After washing with acetone and steaming with an alcohol lamp on an evaporation dish twice, a light-yellow viscous liquid was obtained, which was the EP-POSS product. After further drying with the alcohol lamp on an asbestos net, yellow EP-POSS powder was obtained by crushing.

\subsection{Synthesis of Low-Viscosity POSS (POSS-L) and High-Viscosity POSS (POSS-H)}

Distilled water, concentrated hydrochloric acid, anhydrous methanol, anhydrous ethanol, and silane coupling agent (KH560) were added into a $500 \mathrm{~mL}$ three-port flask in certain proportions, and the reaction temperature was adjusted to $30^{\circ} \mathrm{C}$ for $8 \mathrm{~h}$. After that, rotary evaporation was carried out to further remove the solvent to obtain low-viscosity POSS under a reaction temperature of $35^{\circ} \mathrm{C}$. The above steps were repeated to obtain high-viscosity POSS.

\subsection{Preparation of the EP-POSS Composite}

Certain quantities of epoxy resin and low-viscosity or high-viscosity POSS were mixed and stirred, then mixed evenly with diaminodiphenylsulfone curing agent at room temperature, before pre-polymerizing for $5 \mathrm{~h}$. Then, the mixture was injected into a heated mold, with bubbles pumped in a vacuum oven for about $1 \mathrm{~h}$. Finally, the molded material was cured and shaped according to a curing process of $75^{\circ} \mathrm{C}$ for $1 \mathrm{~h}$ and $110^{\circ} \mathrm{C}$ for a further $1 \mathrm{~h}$. After cooling to room temperature, a further curing process was carried out at $240^{\circ} \mathrm{C}$ for $3 \mathrm{~h}$. Finally, standard mechanical test specimens were prepared from the samples.

\subsection{Synthesis of EP-POSS-SiO ${ }_{2}$ Nano-Composites}

The EP-POSS-SiO ${ }_{2}$ nano-composites were prepared by mixing POSS with different viscosity levels and a certain proportion of nano- $\mathrm{SiO}_{2}$ in acetone for $10 \mathrm{~h}$, volatilizing the acetone completely at room temperature.

\subsection{Characterization}

Contact angle testing (CA): Contact angle testing (CA) was conducted with $4 \mu \mathrm{L}$ droplets of water using a Krüss DSA 30 (Krüss Company, Ltd., Hamburg, Germany) device at ambient temperature. WCAs (water contact angles) were measured at least three times for each sample at different spots.

Scanning electron microscopy (SEM)/energy-dispersive spectrometry (EDS): SEM/EDS study was carried out using a Hitachi model S3000H field emission device (Tokyo, Japan), (SM2082EDS Shenzhen Zhixingfeng Technology Co. Ltd., Shenzhen, China) for carbon steel surfaces corroded for $12 \mathrm{~h}$ in $1 \mathrm{M} \mathrm{HCl}$ solution.

Fourier infrared spectroscopy (FTIR): the structure of the EP-POSS was characterized via attenuated total reflection Fourier transform infrared spectroscopy (ATR-FTIR, Guangzhou zhebo testing technology co., LTD, Thermo Scientific, Guangzhou, China).

X-ray photoelectron spectroscopy (XPS): The elemental composition of the EP-POSS surface was determined via X-ray photoelectron spectroscopy (XPS), conducted in an ultrahigh-vacuum chamber equipped with an X-ray photoelectron spectrometer (SPECS Phoibos $100 \mathrm{MCD}$ analyzer) (Berlin, Germany) and a non-monochromatized Al K $\alpha$ X-ray source (SPECS XR 50).

Transmission electron microscopy (TEM): TEM was conducted using a Tecnai G2 Spirit Twin12 microscope (Tecnai G2 Spirit Twin 12; FEI Company, Czech Republic). The samples were cut at room temperature using an Leica Ultracut UCT ultramicrotome (Leica Microsystems, Inc., Tokyo, Japan). The $50 \mathrm{~nm}$ ultrathin sections were collected on a 
microscopic grid, covered with a $4 \mathrm{~nm}$ carbon layer in order to limit sample damage in the electron beam, and observed in the TEM microscope at $120 \mathrm{kV}$ using bright field imaging. Thermogravimetric analysis (TGA): Mass loss/temperature curves were obtained using a Perkin-Elmer TGA7 device (TGA4000 (PerkinElmer, USA)). The samples were measured at a heating rate of $10{ }^{\circ} \mathrm{C} / \mathrm{min}$. Nitrogen was used as a purge gas.

Si-nuclear magnetic resonance spectroscopy (Si-NMR): Si-NMR was carried out using a Bruke AVANCE $400 \mathrm{MHz}$ (Bruke, Germany) superconducting nuclear magnetic resonance spectrometer, with DMSO as the solvent and TMS as the internal standard. Testing was carried out at $25^{\circ} \mathrm{C}$.

Differential scanning calorimetry (DSC): DSC was performed on a TA Instruments (New Castle, DE, USA) Q20 model using 3-6 mg of sample at a heating rate of $10^{\circ} \mathrm{C} \mathrm{min}-1$ from 40 to $350^{\circ} \mathrm{C}$ under a nitrogen atmosphere.

Atomic force microscopy (AFM): AFM was conducted using a Digital Instruments NanoScope III (Digital Instruments (DI), Santa Barbara, CA, USA) equipped with a J scanner; the scanning range was $150 \mu \mathrm{m}$, the force constant was $10 \mathrm{~N} / \mathrm{m}$, and the tip radius was $10 \mathrm{~nm}$ (NT-MDT).

Flexural performance: the flexural test method followed ASTM D790; the specimen size was $3 \times 12.7 \times 60 \mathrm{~mm}^{3}$ and the test rate was $1 \mathrm{~mm} / \mathrm{min}$.

Impact performance: The impact test method followed ASTM D6110; the specimen size was $4 \times 12.7 \times 125 \mathrm{~mm}^{3}$.

\section{Results}

\subsection{EP-POSS Synthesis Factors}

3.1.1. The Relationship between the Solvent Volume Ratio of Xylene and Isopropanol and the Yield of EP-POSS

Figure 2 displays the relationship between the xylene/isopropanol solvent volume ratio and the EP-POSS yield with $4 \%$ catalyst at $80{ }^{\circ} \mathrm{C}$, a raw material hydrolysis time of $12 \mathrm{~h}$, and condensation time of $180 \mathrm{~min}$. It can be seen that under the above conditions, the yield of the product increased first and then decreased; the maximum yield was $94 \%$ when the volume ratio of xylene and isopropanol was 0.5 .

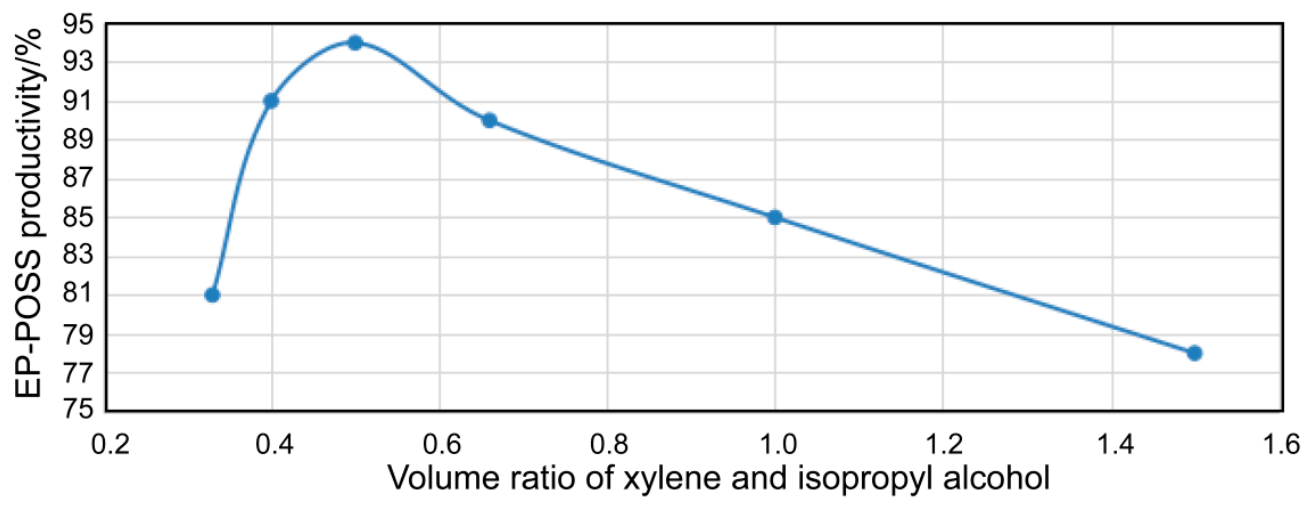

Figure 2. A curve relating the xylene/isopropanol volume ratio with the EP-POSS yield.

\subsubsection{Relationship between Heating Time and EP-POSS Yield}

Figure 3 shows the relationship between the heating time and EP-POSS yield under the conditions of $4 \%$ catalyst, equal volumes of isopropanol and xylene in the mixed solvent, a raw material hydrolysis time of $12 \mathrm{~h}$, and a heating temperature of $80^{\circ} \mathrm{C}$. It can be seen that under the above conditions, the yield of the product first increased with increasing heating time, then decreased to $90 \%$. The product yield was the highest when the heating time was $180 \mathrm{~min}$. This indicates that extension of the condensation time leads to an increase in product yield. However, when the heating time is too long, it may also cause side reactions. The above experiment results show that the maximum yield can reach $94 \%$ under the 
conditions of $4 \%$ catalyst, 1:1 volume ratio of isopropanol to xylene, and condensation time of $180 \mathrm{~min}$ at $80^{\circ} \mathrm{C}$.

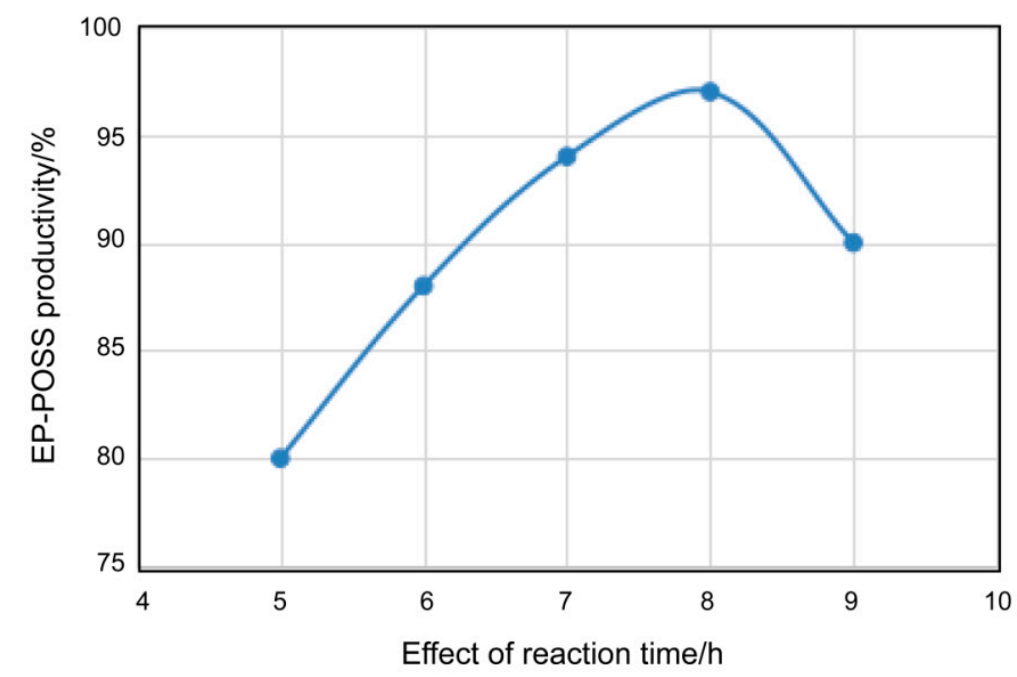

Figure 3. The relationship between heating time and EP-POSS yield.

\subsection{Surface Structure Composition}

The chemical composition of the EP-POSS coating was investigated via FTIR, Si NMR, and XPS measurements. The FTIR and Si NMR spectra are shown in Figure 4. As can be seen in Figure 4, the peaks at $2935 \mathrm{~cm}^{-1}, 1020 \mathrm{~cm}^{-1}$, and $850 \mathrm{~cm}^{-1}$ are the $\mathrm{C}-\mathrm{H}$ stretching vibration, the characteristic peak of the $\mathrm{C}-\mathrm{O}$ ether structure, and the Si-C stretching vibration, respectively. The sharp peak at $1092 \mathrm{~cm}^{-1}$ is attributed to the cage-like $\mathrm{Si}-\mathrm{O}-\mathrm{Si}$ opposition stretching vibration. In addition, the characteristic peaks of alcoholic hydroxyl groups at 3200-3500 $\mathrm{cm}^{-1}$ disappeared, indicating that the KH 560 was completely consumed. In the Si NMR spectrum of EP-POSS, there is a sharp peak at -83.0 ppm, suggesting that most of the Si elements are in the same chemical environment, and the main target product is a symmetrical cage structure.
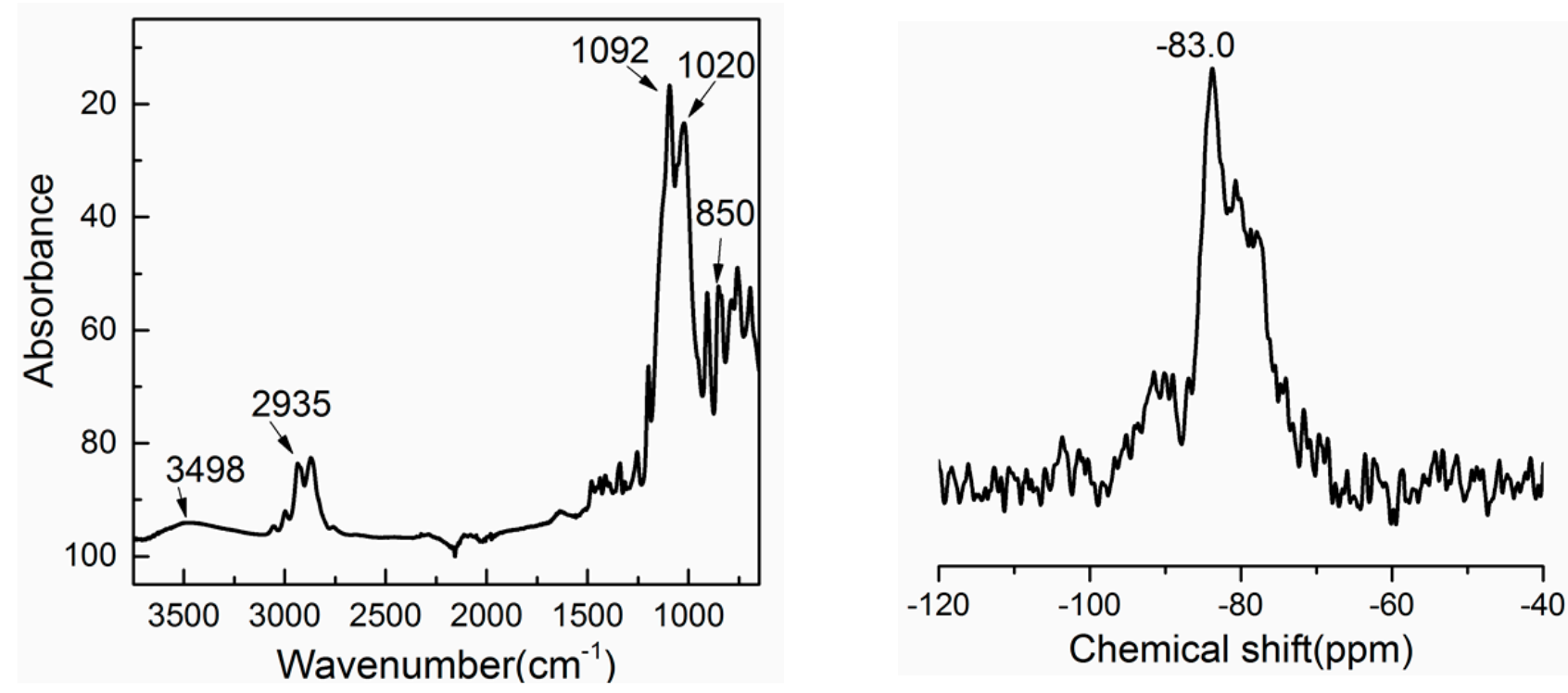

Figure 4. FT-IR (left) and Si NMR (right) spectra of EP-POSS.

The XPS full spectrum and silicon spectrum are shown in Figure 5. The element structure and content data obtained after peak fitting of each element are shown in Table 1. 
It was found that the EP-POSS hydrophobic coating was composed of $\mathrm{C}, \mathrm{O}$, and $\mathrm{Si}$ elements. The structural contents of $\mathrm{C}-\mathrm{Si}$ and $\mathrm{Si}-\mathrm{O}$ were $7.30 \%$ and $0.54 \%$, respectively, which indicates that the $\mathrm{Si}$ element exists in the two structures $\mathrm{C}-\mathrm{Si}$ and $\mathrm{Si}-\mathrm{O}$ after the reaction, without other by-products. At the same time, the content of the $\mathrm{Si}-\mathrm{O}$ structure was significantly lower than that of the $\mathrm{C}-\mathrm{Si}$ structure. This is due to the fact that the cage structure of POSS reduces the detection sensitivity of the Si-O structure.
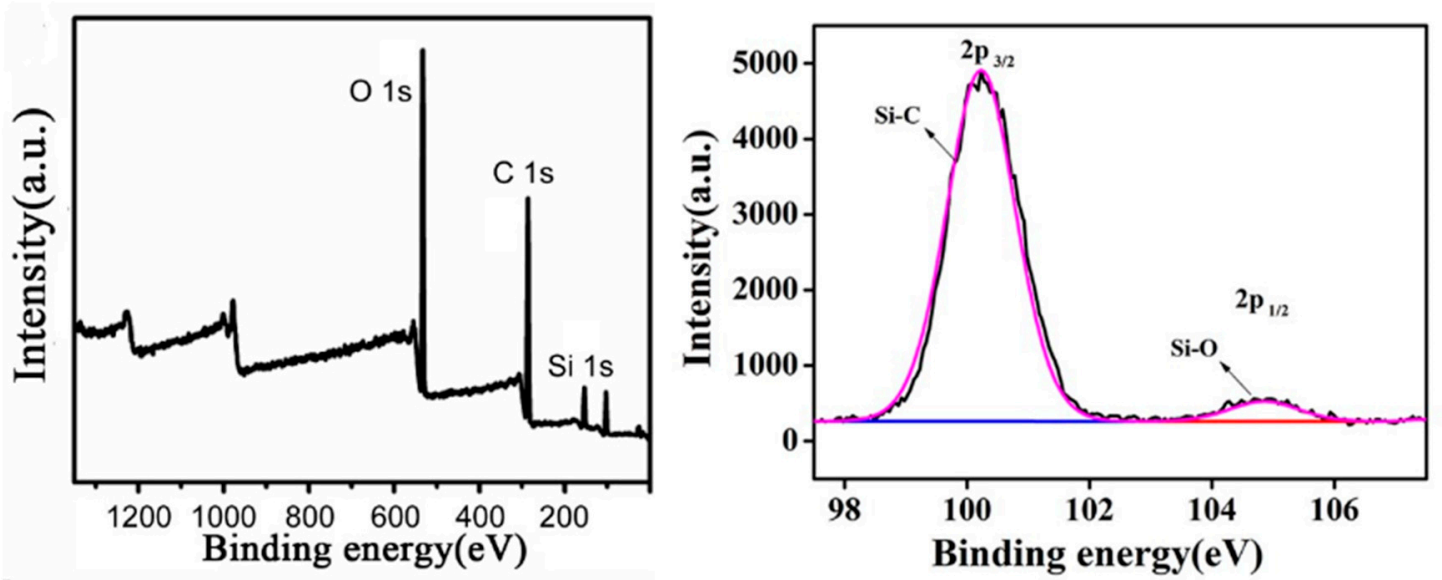

Figure 5. The XPS full spectrum and Si spectrum of EP-POSS.

Table 1. As can be seen in Figure 4, the peaks at $2935 \mathrm{~cm}^{-1}, 1020 \mathrm{~cm}^{-1}$, and $850 \mathrm{~cm}^{-1}$ are the $\mathrm{C}-\mathrm{H}$ stretching vibration, the characteristic peak of the $\mathrm{C}-\mathrm{O}$ ether structure, and the $\mathrm{Si}-\mathrm{C}$ stretching vibration, respectively.

\begin{tabular}{cccccc}
\hline Structure & $\mathrm{Si}-\mathrm{C}$ & $\mathrm{Si}-\mathrm{O}$ & $\mathrm{C}-\mathrm{H}$ & $\mathrm{C}-\mathrm{O}$ & $\mathrm{C}-\mathrm{N}$ \\
\hline Content $/ \%$ & 7.30 & 0.54 & 64.61 & 27.47 & 0.12 \\
\hline
\end{tabular}

\subsection{Microscopic Morphology Analysis}

The microscopic morphology of the EP-POSS coating was investigated via FE-SEM (field emission scanning electron microscopy), transmission electron microscopy (TEM), and atomic force microscopy (AFM) measurements. Figure 6a,b shows SEM images of the EP-POSS film. It can be seen that the coating was composed of a large number of particles, and the particle size was mainly distributed in the micron and nanometer scale, approximately 5-100 $\mu \mathrm{m}$, with some small particles with diameter 100-300 $\mathrm{nm}$ forming the micro-nano composite rough structure. This nano-micro structure can greatly improve the hydrophobic performance of the coating, which is consistent with the CA results.

As shown in Figure 6c,d, the EP-POSS was investigated via energy-dispersive X-ray spectroscopy (EDS). The EDS mapping of the EP-POSS hybrid film further confirmed the existence of $\mathrm{C}, \mathrm{O}$, and $\mathrm{Si}$ elements, so the results of the EDS were consistent with those of the XPS test. Figure 6e,f shows AFM images of the EP-POSS at different magnifications. It shows that the surface of the EP-POSS was composed of an oriented microstructure similar to the cage structure observed in the high-magnification AFM image, suggesting that the POSS structure was within the epoxy resin.

Figure $6 \mathrm{~g}$, h shows the TEM diagrams of EP-POSS hybrid material. To facilitate comparison with the background, the TEM spectrum was observed at the edge of the film. The TEM showed that the black spot at about $1 \mathrm{~nm}$ was EP-POSS, which was uniformly distributed in the epoxy resin without any large-area agglomeration. The above results prove that EP-POSS achieved molecular dispersion in the epoxy resin and had a good hydrophobic microstructure. 


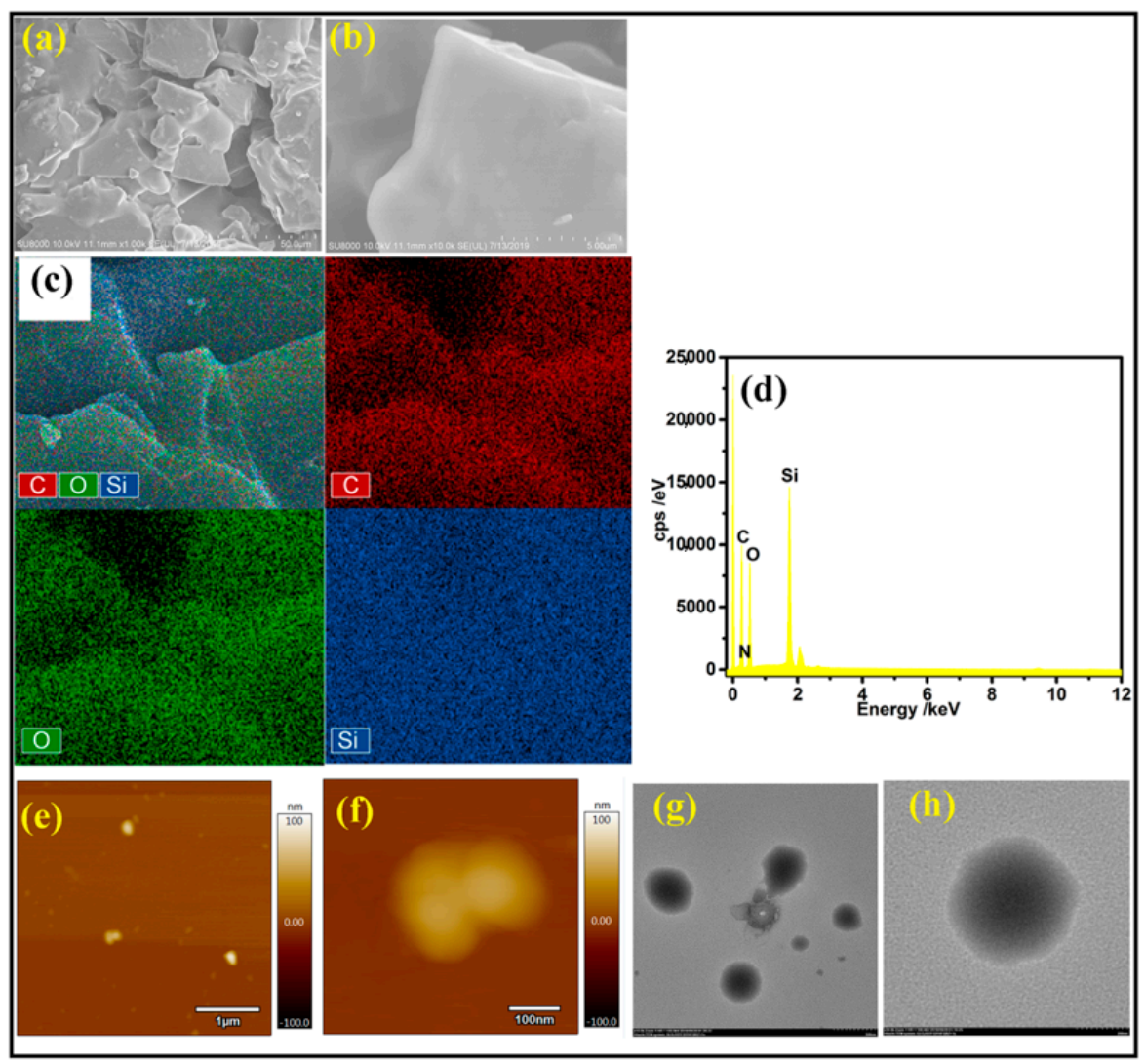

Figure 6. SEM images (a,b), EDS mapping and EDS elemental contents (c,d), atomic force microscopy (AFM) images $(\mathbf{e}, \mathbf{f})$, and transmission electron microscopy (TEM) images (g,h) of EP-POSS.

\subsection{Hydrophobicity and Light Transmittance Testing}

In order to verify the hydrophobic performance, contact angle (CA) measurements were carried out. As shown in Figure 7, the contact angle of EP-POSS was $125^{\circ}$, which is higher than those of other epoxy resins with hanging POSS groups and most resins, even PTFE(poly tetra fluoroethylene) [22-26], indicating that EP-POSS has good hydrophobicity and can be used as a hydrophobic material.



Figure 7. Contact angle measurement of EP-POSS.

Protective coatings for solar panels have higher requirements for light transmittance. If the hydrophobicity is increased, but the light transmittance is reduced, the material does not have application value. The transmittance was tested by examining the UV-vis spectrum. As shown in Figure 8, 60\% of visible light passed through an EP-POSS film with 
a thickness of $200 \mu \mathrm{m}$, indicating that POSS was homogeneously dispersed in the epoxy resin matrix at the molecular level. However, the film's light transmittance of $60 \%$ is too low, and is attributed to yellowing of the film during the drying process with an alcohol lamp. This problem will be addressed in future work.

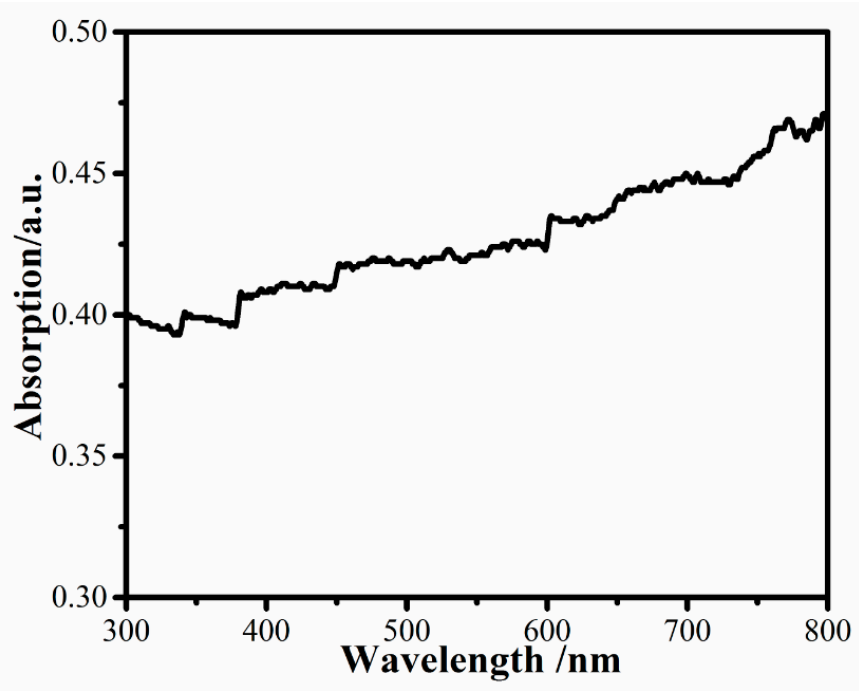

Figure 8. UV-vis spectrum of EP-POSS.

\subsection{Thermal Performance}

The introduction of POSS can usually improve the thermal performance of a material. Considering the higher temperature of the actual use environment, DSC and TGA tests were performed on EP-POSS. The test results are shown in Figure 9. It can be seen from Figure 9 that the initial decomposition temperature of EP-POSS is $354{ }^{\circ} \mathrm{C}$, higher than those of most epoxy resins. This is contributed by the POSS rigid groups in the structure. DSC testing showed that EP-POSS does not undergo a pyrolysis reaction before $354{ }^{\circ} \mathrm{C}$; the first thermal decomposition reaction peak occurred at $406^{\circ} \mathrm{C}$, and then it degraded rapidly. The thermal experimental results show that EP-POSS has higher thermal performance than other commercial epoxy resins and is suitable for high-temperature working conditions.

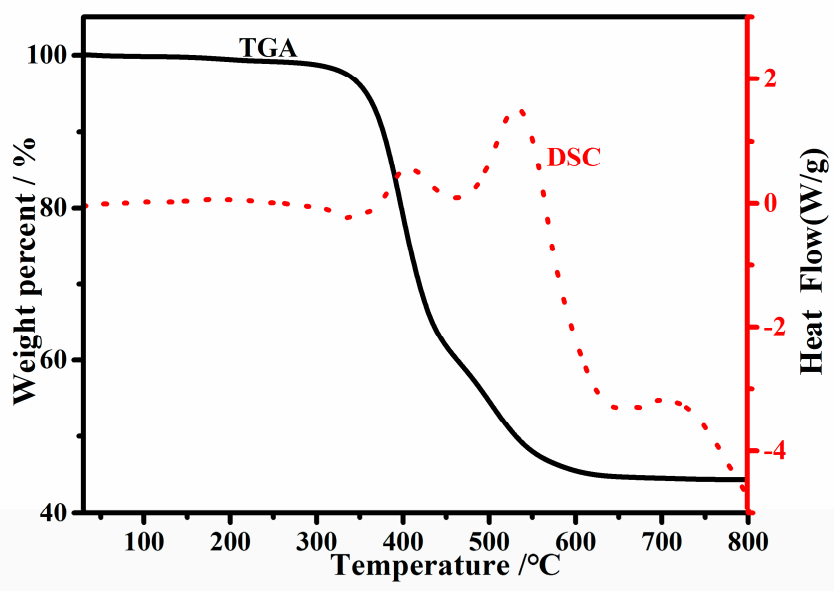

Figure 9. Differential scanning calorimetry (DSC) and thermogravimetric analysis (TGA) curves of EP-POSS.

\subsection{Mechanical Performance}

The prepared EP-POSS nanocomposite has excellent hydrophobicity and light transmittance, but can its mechanical properties meet the requirements of a protective coating? 
For the seven nanocomposites prepared, the mechanical properties were characterized by bending and impact performance testing. The bending strength and modulus are shown in Figure 10, the impact test results are shown in Figure 11, and all the test results are listed in Table 2.
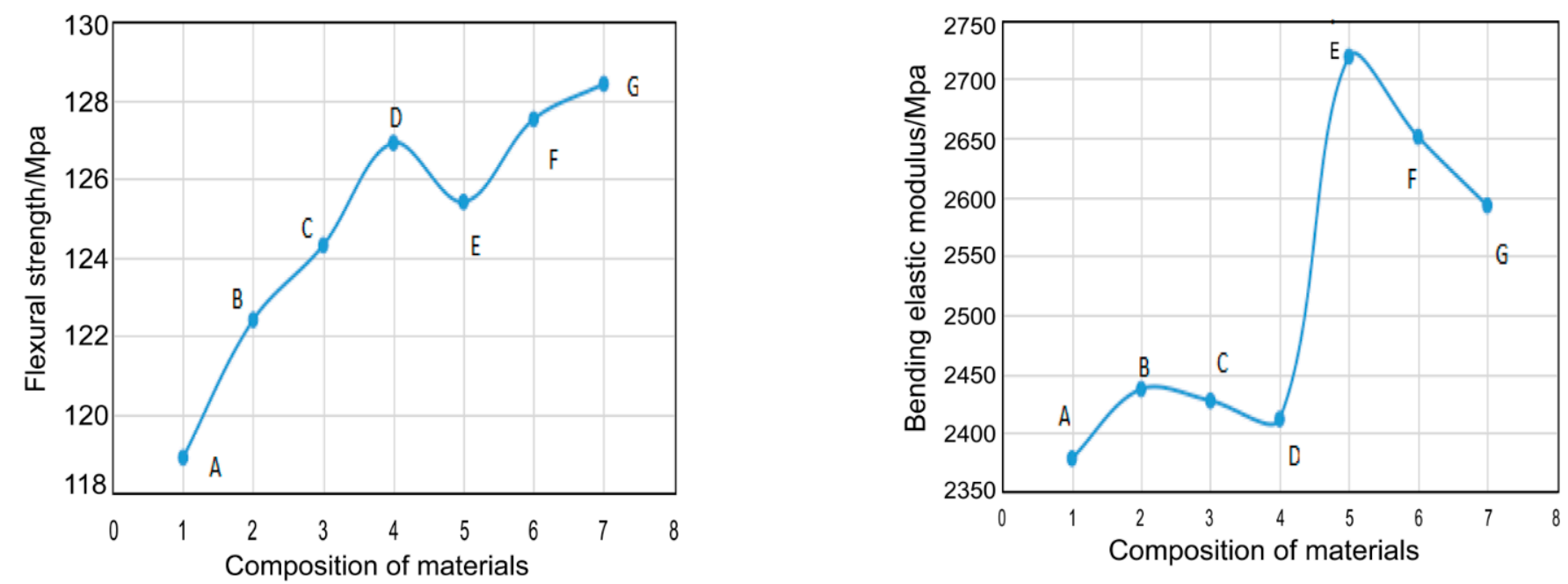

Figure 10. The bending strength (left) and modulus (right) curves of different material systems for A: EP, B: EP-POSS-L, C: EP-POSS-M, D: EP-POSS-H, E: EP-SiO2-POSS-L, F: EP-SiO2-POSS-M, and G: EP-SiO2-POSS-H.

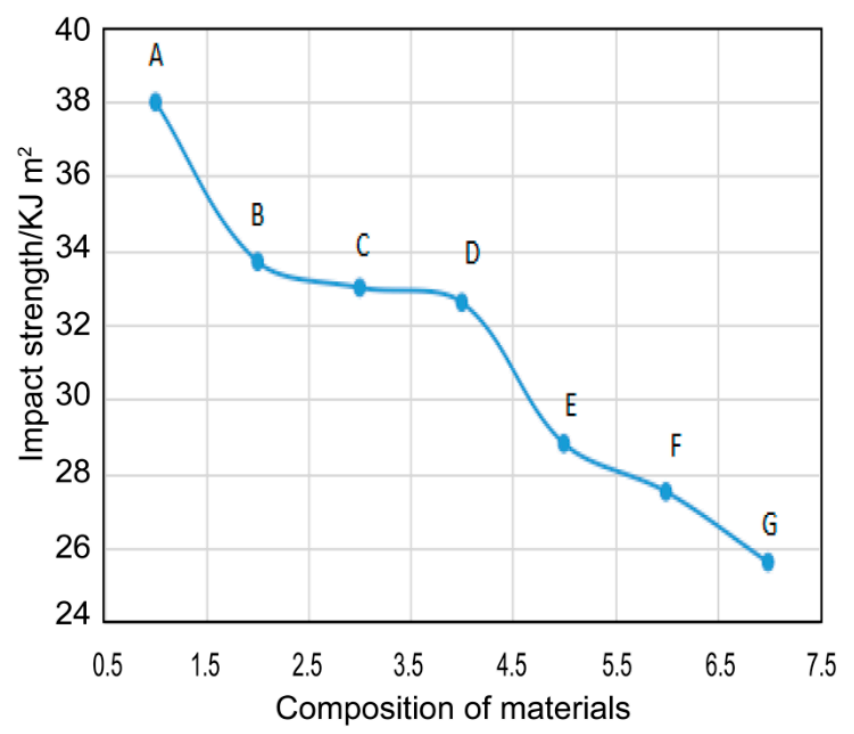

Figure 11. The impact strength curves of the different EP-POSS systems.

Table 2. The mechanical properties of the different EP-POSS systems.

\begin{tabular}{|c|c|c|c|}
\hline $\begin{array}{l}\text { Composition of } \\
\text { Materials }\end{array}$ & $\begin{array}{c}\text { Bending Strength } \\
(\mathrm{MPa})\end{array}$ & $\begin{array}{l}\text { Bending Modulus } \\
\text { (MPa) }\end{array}$ & $\begin{array}{c}\text { Impact Strength } \\
\left(\mathrm{kJ} \cdot \mathrm{m}^{-2}\right)\end{array}$ \\
\hline $\mathrm{EP}$ & 118.9 & 2378.5 & 38.0 \\
\hline EP-POSS(L) & 122.4 & 2437.3 & 33.7 \\
\hline EP-POSS(M) & 124.3 & 2427.4 & 33.0 \\
\hline EP-POSS(H) & 126.9 & 2411.8 & 32.6 \\
\hline EP-SiO $2-P O S S(L)$ & 125.4 & 2718.6 & 28.8 \\
\hline EP-SiO $2-P O S S(M)$ & 127.5 & 2650.8 & 27.5 \\
\hline $\mathrm{EP}-\mathrm{SiO}_{2}-\mathrm{POSS}(\mathrm{H})$ & 128.4 & 2592.6 & 25.6 \\
\hline
\end{tabular}


It can be seen from Figure 10 that the bending strength and modulus of EP-POSS showed a certain improvement compared with those of epoxy resin. This is because the introduction of the POSS rigid group increases the mechanical strength. On the contrary, the introduction of POSS leads to a reduction in impact performance, as seen in Figure 9. After adding rigid $\mathrm{SiO}_{2}$ nanoparticles with a size of $30 \mathrm{~nm}$, the bending strength was further improved, and the resulting material could be used as a hydrophobic protective coating. Besides this, the high-viscosity EP-POSS-H had higher bending strength, which is attributed to its higher structural regularity, increasing the crosslinking density to obtain good properties.

In order to test the surface hydrophobicity changes of solar panels in the actual environment, simulation testing was conducted using samples of size $26 \mathrm{~mm} \times 76 \mathrm{~mm}$ and a $500 \mathrm{~g}$ weight. The test method is shown in Figure 12. The sample was put on the sandpaper with a $500 \mathrm{~g}$ weight as the load on top, and then an external force was applied on the sample. It was moved $25 \mathrm{~cm}$ in a straight line, then rotated $90^{\circ}$ clockwise after each wear to ensure that the sample was operated evenly from four directions. After 200 cycle operations, the contact angle of the sample was still $115^{\circ}$, indicating that the prepared EP-POSS hydrophobic coating has good abrasion resistance and can be used as a protective coating for solar panels.

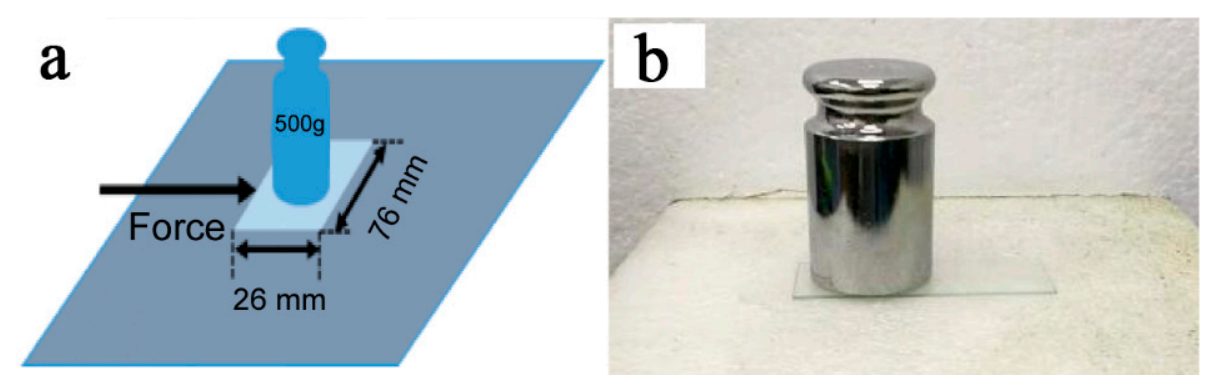

Figure 12. The EP-POSS friction test method.

\section{Conclusions}

EP-POSS nanocomposite with POSS groups in the main chain structure was prepared by a simple synthesis method under acidic conditions, and the yield reached $94 \%$. The contact angle of the EP-POSS was $125^{\circ}$, showing excellent hydrophobicity due to the micronano structure of the surface. The surface $\mathrm{Si}$ element exists as $\mathrm{Si}-\mathrm{C}$ bonds, which have a main chain shielding effect and are beneficial to improving the material's hydrophobicity. At the same time, EP-POSS showed excellent heat resistance: its initial decomposition temperature was $354^{\circ} \mathrm{C}$. The flexural strength increased from 118.9 MPa to $126.9 \mathrm{MPa}$, but the impact performance decreased from 38.0 MPa to $32.6 \mathrm{MPa}$. This is because the POSS group in the skeleton structure improves its rigidity and thermal stability. In addition, the POSS group enhances the hardness of EP-POSS, and the flexibility of the epoxy segment improves the abrasion resistance. The contact angle of EP-POSS was $115^{\circ}$ after 200 rubbing operations, indicating that it can be used as a protective coating for solar panels.

Author Contributions: Y.F. and P.W. conceived and designed the experiments; L.S. and L.W. performed the experiments; Y.F. analyzed the data and wrote the paper. P.W. reviewed and revised the manuscript. All authors have read and agreed to the published version of the manuscript.

Funding: This work was supported by the National Key Research and Development Program 2018 YFB2100100 and NSFC Grant No. 51677010.

Acknowledgments: I would like to express my great appreciation to my advisor Ping Wang, teacher Lifang Sun, and all my fellows from my research group.

Conflicts of Interest: The authors declare no conflict of interest. 


\section{References}

1. Scott, D.W. Thermal Rearrangement of Branched-Chain Methylpolysiloxanes1. J. Am. Chem. Soc. 1946, 68, 356-358. [CrossRef]

2. Ni, Y.; Zheng, S.; Nie, K. Morphology and thermal properties of inorganic-organic hybrids involving epoxy resin and polyhedral oligomeric silsesquioxanes. Polymer 2004, 45, 5557-5568. [CrossRef]

3. Frank, K.L.; Exley, S.E.; Thornell, T.L.; Morgan, S.E.; Wiggins, J.S. Investigation of pre-reaction and cure temperature on multiscale dispersion in POSS-epoxy nanocomposites. Polymer 2012, 53, 4643-4651. [CrossRef]

4. Matějka, L.; Murias, P.; Pleštil, J. Effect of POSS on thermomechanical properties of epoxy-POSS nanocomposites. Eur. Polym. J. 2012, 48, 260-274. [CrossRef]

5. Jerman, I.; Šurca Vuk, A.; Koželj, M.; Švegl, F.; Orel, B. Influence of amino functionalised POSS additive on the corrosion properties of (3-glycidoxypropyl)trimethoxysilane coatings on AA 2024 alloy. Prog. Org. Coat. 2011, 72, 334-342. [CrossRef]

6. Mishra, K.; Pandey, G.; Singh, R.P. Enhancing the mechanical properties of an epoxy resin using polyhedral oligomeric silsesquioxane (POSS) as nano-reinforcement. Polym. Test. 2017, 62, 210-218. [CrossRef]

7. Yang, H.; He, C.; Russell, T.P.; Wang, D. Epoxy-polyhedral oligomeric silsesquioxanes (POSS) nanocomposite vitrimers with high strength, toughness, and efficient relaxation. Giant 2020, 4, 100035. [CrossRef]

8. Laine, R.M.; Roll, M.F. Polyhedral Phenylsilsesquioxanes. Macromolecules 2011, 44, 1073-1109. [CrossRef]

9. Zhang, W.; Camino, G.; Yang, R. Polymer/polyhedral oligomeric silsesquioxane (POSS) nanocomposites: An overview of fire retardance. Prog. Polym. Sci. 2017, 67, 77-125. [CrossRef]

10. Walczak, M.; Januszewski, R.; Franczyk, A.; Marciniec, B. Synthesis of monofunctionalized POSS through hydrosilylation. J. Organomet. Chem. 2018, 872, 73-78. [CrossRef]

11. Kuo, S.-W.; Chang, F.-C. POSS related polymer nanocomposites. Prog. Polym. Sci. 2011, 36, 1649-1696. [CrossRef]

12. Gao, Q.; Qi, S.; Wu, Z.; Wu, D.; Yang, W. Synthesis and characterization of functional ladder-like polysilsesquioxane and their hybrid films with polyimide. Thin Solid Film. 2011, 519, 6499-6507. [CrossRef]

13. Qian, Y.; Wei, P.; Zhao, X.; Jiang, P.; Yu, H. Flame retardancy and thermal stability of polyhedral oligomeric silsesquioxane nanocomposites. Fire Mater. 2013, 37, 1-16. [CrossRef]

14. Zhang, Z.; Gu, A.; Liang, G.; Ren, P.; Xie, J.; Wang, X. Thermo-oxygen degradation mechanisms of POSS/epoxy nanocomposites. Polym. Degrad. Stab. 2007, 92, 1986-1993. [CrossRef]

15. Ramírez, C.; Rico, M.; Torres, A.; Barral, L.; López, J.; Montero, B. Epoxy/POSS organic-inorganic hybrids: ATR-FTIR and DSC studies. Eur. Polym. J. 2008, 44, 3035-3045. [CrossRef]

16. Boček, J.; Matějka, L.; Mentlík, V.; Trnka, P.; Šlouf, M. Electrical and thermomechanical properties of epoxy-POSS nanocomposites. Eur. Polym. J. 2011, 47, 861-872. [CrossRef]

17. Sharma, A.K.; Sloan, R.; Wiggins, J.S. Epoxy hybrid networks with high mass fraction molecular-level dispersion of pendant polyhedral oligomeric silsesquioxane (POSS). Polymer 2017, 114, 298-310. [CrossRef]

18. Jiri, B.; Martina, U.; Adam, S. Epoxy networks reinforced with polyhedral oligomeric silsesquioxanes: Structure and segmental dynamics as studied by Solid-State NMR. Macromolecules 2008, 41, 372-386. [CrossRef]

19. Rashid, E.S.A.; Ariffin, K.; Kooi, C.C.; Akil, H.M. Preparation and properties of POSS/epoxy composites for electronic packaging applications. Mater. Des. 2009, 30,1-8. [CrossRef]

20. Lin, P.-H.; Khare, R. Molecular Simulation of Cross-Linked Epoxy and Epoxy-POSS Nanocomposite. Macromolecules 2009, 42, 4319-4327. [CrossRef]

21. Chen, M.; Qu, Y.; Yang, L.; Gao, H. Structures and antifouling properties of low surface energy non-toxic antifouling coatings modified by nano-SiO 2 powder. Sci. China Ser. B Chem. 2008, 51, 848-852. [CrossRef]

22. Chi, B.; Hou, S.; Liu, G.; Deng, Y.; Zeng, J.; Song, H.; Liao, S.; Ren, J. Tuning hydrophobic-hydrophilic balance of cathode catalyst layer to improve cell performance of proton exchange membrane fuel cell (PEMFC) by mixing polytetrafluoroethylene (PTFE). Electrochim. Acta 2018, 277, 110-115. [CrossRef]

23. Bryant, P.M.; Szili, E.J.; Whittle, T.; Park, S.-J.; Eden, J.G.; Al-Bataineh, S.; Steele, D.A.; Short, R.D.; Bradley, J.W. The use of a micro-cavity discharge array at atmospheric pressure to investigate the spatial modification of polymer surfaces. Surf. Coat. Technol. 2010, 204, 2279-2288. [CrossRef]

24. Chen, S.; Yang, M.; Han, Y.; Liu, H.; Zou, H. Hydrophobically modified sustainable bio-based polyurethane for controllable release of coated urea. Eur. Polym. J. 2020. [CrossRef]

25. Dai, M.; Zhai, Y.; Zhang, Y. A green approach to preparing hydrophobic, electrically conductive textiles based on waterborne polyurethane for electromagnetic interference shielding with low reflectivity. Chem. Eng. J. 2020. [CrossRef]

26. Shiraki, Y.; Yokoyama, H. Novel hydrophobic and oleophobic surfaces using polyurethane with hydrogenated polyisoprene soft segment. Mater. Today Commun. 2020, 24, 101243. [CrossRef] 